\title{
A natureza na Filosofia da TeCNOLOGia DE Albert Borgmann
}

\author{
Tiago Mesquita Carvalho ${ }^{1}$
}

(Centro de Filosofia das Ciências, Universidade de Lisboa)

\section{Introdução}

A questão de como estabelecer uma relação consentânea com a natureza é central à ética ambiental e à ética da tecnologia. Contudo, o melhor conhecimento preditivo disponível para orientar as nossas acções revela-se hoje aquém do conhecimento que alimenta a escalada tecnológica. A propósito da incapacidade de prever os efeitos a jusante das nossas acções tecnologicamente mediadas, Beckert afirma que "o poder que advém do desenvolvimento tecnocientífico é, ele mesmo, gerador de uma fragilidade inultrapassável, ao destituir o homem daquilo que estaria justamente em seu poder enquanto sujeito, a saber, a autonomia". E conclui: "Daí a relação não-contraditória, mas antes de estrita proporcionalidade, entre acréscimo de poder e acréscimo de fragilidade"2.

Assinale-se que as possíveis vantagens ou desvantagens da tecnologia para o bem-estar ou para o florescimento humano têm sido um tema desde o Iluminismo; vários autores dessa época acreditavam que a aplicação progressiva da ciência tinha o potencial de prover a humanidade com um controlo ilimitado sobre a natureza; outra crença relacionava-se com a capacidade da razão humana compreender a realidade, antecipar o futuro e da tecnologia ser usada somente para fins apropriados. Esta visão optimista

\footnotetext{
1 borboto@gmail.com

2 Cf. Beckert 2012: p. 101.
}

Philosophica, 47, Lisboa, 2016, pp. 77-92. 
ainda hoje está presente; a tecnologia é vista como um instrumento neutro do progresso social e económico e que torna invariavelmente melhor a vida das pessoas; como meio apto a atingir um certo fim, a tecnologia é encarada como um poder facilitador para granjear a vida boa.

De um modo geral, o optimismo tecnológico e as crenças associadas ao determinismo tecnológico têm favorecido a adopção acrítica de novidades tecnológicas, tal como caucionam soluções tecnológicas para problemas ecológicos e de saúde humana. A crença numa solução tecnológica mantém a promessa de que qualquer problema pode ser resolvido sem que para tal seja necessário modificar, aliviar ou sacrificar certos estilos de vida, certas instituições ou certos hábitos individuais e culturais. A demanda tecnológica, porém, não fornece igualmente uma resposta taxativa à questão de saber em que consiste afinal a vida boa nem como essa noção se articula com a necessária presença da natureza para essa resposta. Neste sentido, intentamos averiguar, a partir da perspectiva do filósofo Albert Borgmann, a plausibilidade de reformar a tecnologia, através de um exame à sua obra filosófica, com particular destaque para o seu Technology and the Character of Contemporary Life de 1984.

\section{O paradigma do dispositivo de Borgmann}

O que é a vida boa e como se relaciona a tecnologia com esse fim? O facto de a tecnologia reconfigurar estilos de vida e a natureza através dos seus dispositivos é já em si parte da resposta. Enquanto a substância da vida boa permanecer tecnologicamente mal definida, a reforma real será "impossível ou inconsequente, uma vez que ignorará tal factor de peso"3. A tese de Borgmann é que vivemos implicados pela tecnologia; embora esta não determine nem domine inexoravelmente as nossas vidas, afecta a maneira como a vivemos, em particular se tivermos nascido numa nação industrial. A forma como a tecnologia nos governa não força directamente as pessoas aos seus ditames nem é vista com ressentimento ou resistência; ao invés, o governo da tecnologia é alcançado através de padrões imperceptíveis pelos quais nos orientamos.

$\mathrm{Na}$ sua análise do impacte da tecnologia na vida contemporânea, Borgmann remonta à ideia da sua promessa original para sublinhar al-

3 Cf. Borgmann 1984: 98. Ver também Borgmann 2006: 30. É comum aos filósofos da tecnologia pugnarem pelo reconhecimento de que a resposta cabal ao que é a substância da vida boa obriga necessariamente a um exame do ambiente material em que vivemos. 
guns aspectos que parecem ter ficado esquecidos. A tecnologia é, antes de mais, uma promessa de controlo das forças da natureza e da cultura com o propósito de aliviar os seres humanos "da indigência, do trabalho e de enriquecer, num sentido lato, as suas vidas" . Embora esta visão da tecnologia pareça a Borgmann excessivamente determinista, ela é ilustrativa do modo como pretende a tecnologia tomar o mundo; é porém determinista manter igualmente que a liberdade e o enriquecimento promovidos pela tecnologia são apenas e só ajustados pela responsabilidade política e pela justiça social.

Borgmann nota que as noções de liberdade e enriquecimento se conjugam na questão da disponibilidade de uma dada tecnologia. O modo como os seus benefícios estão tecnologicamente disponíveis implica pois que eles prometem enriquecer as vidas humanas sem lhes imporem qualquer fardo; algo está disponível nesta acepção, se se tiver "tornado instantâneo, ubíquo, seguro e óbvio"s.

O sentido desta disponibilidade só fica patente ante a introdução da diferença entre dois conceitos centrais: os dispositivos e as coisas; uma coisa, para Borgmann, é inseparável do seu contexto, do seu mundo; uma coisa, aliás, invoca e obriga a um envolvimento multidimensional com ela, nunca providenciando um e um só benefício. O exemplo da lareira é esclarecedor ${ }^{6}$; embora uma lareira gere calor, o mundo que ela acarreta, para acontecer e manter-se, expande-se na vida de maneiras bastante complexas; uma lareira é um centro atractivo do lar e na língua portuguesa não é coincidência ambas as palavras derivarem da mesma raiz ${ }^{7}$; ela foi outrora o centro das casas porque fornecia luz, calor e permitia a confecção de refeições, convocando os habitantes para a fruição de um espaço vivido e criado através de tarefas comuns; tais tarefas destinadas à criação do fogo, embora sejam laboriosas, são também lúdicas e cativam os sentidos de várias e múltiplas formas: o corte, a selecção e a recolha de lenha, a noção de que as próprias características da lenha mudam consoante as estações do ano, a perícia para criar o fogo, a noção de que graças aos esforços de todos se venceu a ameaça do frio e se conquistou um conforto enquanto se

4 Cf. Borgman 1984: 36.

Ibid. p. 41.

6 Cf. Borgmann 2006: 114.

7 Os Lares eram, entre os romanos e os etruscos, os deuses protectores do domicílio; na cozinha, Lar era o local onde se acendia o fogo; por extensão de sentido, passou a designar a casa de habitação familiar; é curioso notar que designa também a superfície onde se cozia o pão. 
presenciam as chamas e o cheiro que se liberta dos tocos de madeira; todos estes aspectos podem corresponder a uma visão algo bucólica mas os pontos que Borgmann retira deste exemplo prendem-se com outra lógica.

Tais tarefas implicam um adestramento na aquisição de competências e a fidelidade a hábitos cooperativos com outros seres humanos; as práticas e os os hábitos invocados por cada coisa são-lhe internos e podem então ser mais consentâneos com o modo como pautamos dever ser uma vida boa; uma coisa tem pois o condão de instigar o envolvimento corpóreo e sensível com o seu mundo e quanto mais fidelidade houver à sua prossecução, mais aprofundamento e enraizamento no seu mundo advêm. Quaisquer limitações ao adestramento e à aprendizagem de competências confinam o envolvimento de uma pessoa com o mundo a áreas mais limitadas.

Um dispositivo como um aquecedor central, pelo contrário, trabalha de modo bastante diferente ao da lareira. O seu propósito comum é comparável por ambos fornecerem calor a um dado lar ou dependência, embora de maneiras bastante diferentes. $\mathrm{O}$ aquecedor central provê-nos de calor mas livra-nos de todos os outros elementos envolvidos na sua geração e que a lareira mantém explícitos. São esses elementos que estão ocultos no mecanismo do dispositivo, o qual não nos exige nenhuma competência especial, nenhum conhecimento ou nenhuma destreza particulares; esta falta de exigência é tanto menor quanto menor é a estranheza perante a sua presença.

Segundo Borgmann, na história da tecnologia os mecanismos dos dispositivos apresentam uma tendência para se tornarem diminutos ou se ocultarem quase por completo; são estas as propriedades do dispositivo pelo qual o bem ou a mercadoria ${ }^{8}$ (neste caso, o calor) é obtido. Cada dispositivo justifica a sua existência através da satisfação do bem que provê. Assim, se o aquecimento central dá calor, o telemóvel permite a comunicação, o automóvel cumpre o transporte, a fast-food é o sucedâneo limite da alimentação e uma aparelhagem estereofónica fornece música. A ênfase, em cada um destes dispositivos, tem em conta a maneira cómoda como cada um torna disponível o bem ou a mercadoria em causa.

\footnotetext{
8 O termo original em Borgmann é commodity; na literatura económica este termo é por vezes traduzido como comodidade; em língua portuguesa a conotação comum deste termo caracteriza mais a sensação de bem-estar e conforto, o que é relevante para análise, mas não denota tanto um objecto; por vezes usa-se bem, produto ou mercadoria; pode haver contudo bens não comerciais, pelo que mercadoria poderá induzir em erro; um bem conserva talvez o sentido de um objecto que pela sua disponibilidade e presença possui implicações para os hábitos que compõem o âmbito moral de uma certa vida. Neste trabalho será usado será usado nesta acepção.
} 
Esta tendência histórica resultou num afã hodierno pela disseminação da disponibilidade dos dispositivos tecnológicos; os obstáculos que pudessem impedir que a sua disponibilidade não fosse apreendida como óbvia ou que a sua utilização não fosse vista como mais ubíqua e instantânea foram progressivamente eliminados; esta tendência apontada por Borgmann explica pois como o próprio espaço e o próprio tempo são encarados como constrangimentos à disponibilidade dos dispositivos e que a tendência para um incremento na velocidade de trocas de informação ou mercadorias seja uma reputada e inevitável consequência; ao mesmo tempo, sublinha Borgmann, todos os dispositivos que nos rodeiam na vida contemporânea tendem a observar uma retracção progressiva do mecanismo que lhes é inerente, enquanto a função que pretendem satisfazer é tornada mais conspícua e proeminente. Esta relação é concomitante: a ocultação e a desfamiliarização do mecanismo corre paralela ao alijamento do dispositivo; caso o mecanismo estivesse presente, teria de reclamar o uso das nossas faculdades e daí a tendência para a sua elisão; o alijamento do dispositivo torna possível, fácil e imediata a prossecução do bem ${ }^{9}$, sem que o modo como esse bem surge seja questionado ou ponderado.

Eis, então, o contraste entre uma coisa e um dispositivo. As qualidades de um dado contexto ou de um certo mundo insinuam-se, derramam-se nas próprias coisas que o constituem ${ }^{10}$; a progressiva substituição de coisas pela disponibilidade dos dispositivos torna pois mais flagrante a perda das qualidades e propriedades de um dado contexto; o mundo das coisas, convidando a um envolvimento e a uma relação duradoura com os seres humanos, é doravante erodido pelo aparecimento dos dispositivos; estes, porém, facultam os respectivos bens através dos mecanismos que permanecem escondidos; cada bem é assim fruído sem qualquer envolvimento com um contexto e sem qualquer estorvo ${ }^{11}$.

Ora, uma das maneiras mais óbvias de tornar os bens obtidos através de dispositivos permanentemente disponíveis é torná-los descartáveis ${ }^{12}$; esta qualidade deriva directamente da ausência de envolvimento com o contexto de uma dada coisa e com a aquisição de competências que ela acarreta; a especialização profunda que eles implicam para providenciarem um dado bem confere um cariz institucional à dependência

9 Cf. Borgmann 1984: 43.

10 Cf. Borgman 1993: 120-121.

11 Em Borgmann os dispositivos promovem o disburdenment, termo que quanto a nós tem conotação ontológica. Podemos traduzi-lo por desenfardo ou desresponsabilização.

$12 \quad$ Ibid. p. 47. 
desses dispositivos. Não é possível reparar, pelo seu próprio desenho, estrutura ou pela especialização exigida, dispositivos como guardanapos, latas de sumo, canetas esferográficas, tal como não é suposto estes objectos apresentarem durabilidade, dado que o cuidado, enquanto envolvimento, está afastado dos dispositivos; o lixo e os seus impactes na natureza estão implícitos na vida contemporânea a partir do momento em que esta foi capturada pela tecnologia na acepção do paradigma do dispositivo.

Sob a superfície da função de cada dispositivo jaz então o mecanismo; este, como se viu, permanece oculto mas ao emular, na sua complexidade, o contexto de uma coisa, esconde também muito do labor social envolvido na sua produção; vela também os recursos naturais utilizados; Borgmann estabelece que esta opacidade, num mundo tecnológico, é de facto uma mais-valia porquanto assinala o carácter descartável das mercadorias e a impossibilidade de estabelecermos, com elas, os compromissos que o contexto de uma coisa possibilitaria. Esta ambiguidade e plasticidade é favorecida e adoptada livremente pelos consumidores: "consumir é pois usar uma entidade isolada providenciada por um dispositivo, mas sem qualquer preparação, ressonância e consequências"13.

O paradigma do dispositivo fornece a possibilidade de uma crítica à tecnologia desde que estejamos preocupados com a perda do envolvimento com as coisas e com a extensão dessa perda; o modo como a natureza é tomada pela tecnologia e como em simultâneo a obvia é porém fundamental para a possibilidade de uma reforma.

\section{A literatura da natureza e a explicação díctica}

Para entendermos a importância que Borgmann concede à sua própria caracterização da tecnologia no carácter da vida contemporânea, é fundamental distinguirmos dois níveis de explicação dos fenómenos; só após esta distinção poderemos apreender o sentido mais profundo que a natureza pode ter numa putativa reforma da tecnologia.

Borgmann nota que qualquer fenómeno é hoje passível de ser explicado através de causas, efeitos e processos em termos de outros fenómenos, agentes ou eventos inseridos em leis causais consideradas sobejamente robustas pela respectiva comunidade cientifica ${ }^{14}$.

$13 \quad$ Ibid. p. 51.

14 Cf. Borgmann 1984: 19. 
A explicação científica é, no seu rigor álgido e no seu formalismo rarefeito, atreita a considerações de um certo artificialismo; a sua linguagem austera e parcimoniosa, na riqueza da sua simplicidade, parece-nos demasiado longe da nossa vida comum, cheia de inúmeras solicitações e estímulos; este tipo de explicação é dedutivo-nomológica uma vez que pode tomar a forma de um silogismo, em que das premissas e das condições iniciais são deduzidas leis empíricas que enquadram os fenómenos; se as condições iniciais e as premissas forem aceites como verdadeiras e as regras de inferência lógica forem seguidas, então a proposição que caracteriza o fenómeno não pode ser recusada como verdadeira. Pela sua evidência, este tipo de explicação é portanto apodíctica ${ }^{15}$, por demonstrar de maneira indubitável a adequação entre um certo fenómeno e um certo sistema formal; trata-se aqui de enfatizar a cogência e não a própria estrutura da explicação científica.

Segundo Borgmann, a explicação apodítica exarada na ciência contemporânea, apesar da maior consistência das suas leis e do seu poder preditivo, não coloca todos os problemas que carecem de explicação, não sendo por conseguinte suficiente para avalizar quais os problemas que carecem de um outro tipo de explicação.

Existe porém um outro tipo de explicação que possui o condão de lograr seleccionar e enaltecer as qualidades essenciais de algo na sua particularidade única. Borgmann apelida-a de explicação dictíca; ela complementa necessariamente a inaptidão da explicação apodítica para invocar um sentido; o étimo indica já que se trata de uma explicação que indica um contexto concreto de enunciação ${ }^{16}$; coloca-nos perante algo que nos ensina pela sua evidência e nos ilumina pela sua eloquência ${ }^{17}$; a arte tem sido a expressão díctica por excelência, articulando-se por vezes, no seu estro invocador, com a filosofia e com a própria religião; mas deve-se hoje reconhecer que as explicações dícticas tradicionais perderam a sua força.

Borgmann asserta que só podemos anelar a um discurso sobre o que deve constituir a vida boa se nos ativermos à presença que as explicações dícticas clamam; tal explicação, sem recurso a métodos dedutivos, motiva-nos a agir pelo seu poder clarificador e metapoético, de apelo aos primeiros princípios, permanecendo, contudo, contestável, precisamente por não encerrar o seu sentido em explicações sistemáticas, mas retirar a sua força do sentido mais profundo das coisas que realmente importam. Ela

\footnotetext{
15 Ibid. p. 20.

16 Do grego deíktikos,ê,ón', que mostra ou demonstra. Cf. Dicionário Houaiss.

17 Cf. Borgmann 1984: 178.
} 
não aspira a ser estruturada ou cogente mas tampouco é por isso arbitrária ou ininteligível, dado que é orientada por apelos que ecoam em todos os seres humanos, por respeitarem à orientação do seu agir e do seu pensar.

Muitas das explicações dícticas têm a sua origem na literatura; consistem em pequenos trechos, passagens ou aforismos que granjeiam enormes sínteses; muitas delas aludem a um travejamento cósmico acerca do lugar do homem na natureza e do modo como ele pode habitá-la; outras referem-se ao poder redentor da natureza para inculcar virtudes, modos de vida ou certos hábitos nos indíviduos; são elaboradas em linguagens de reflexão que solicitam, pela sua brevidade, brilho ou pungência uma avaliação interior do leitor por si próprio ou um convite à experiência demorada em tais situações, fomentando a imaginação moral acerca daqueles horizontes que nos recordam do fundamento inveterante que certas coisas e práticas possuem.

Tal como Rolston III $^{18}$ aponta, a natureza adquire em certas situações uma função tutorial; apesar de os seres vivos, os elementos bióticos e os ecossistemas não serem nem preceptores nem agentes morais num sentido estrito, têm a capacidade de instigar em nós impressões sinestéticas e reflexões concomitantes que adquirem traços com consequências morais para o modo como pretendemos orientar as nossas vidas; há pois que reconhecer que a natureza desperta no sujeito um domínio reflexivo que adquire, não raras vezes, um poder educativo e até normativo e que o coloca directamente no domínio de avaliação de si próprio e da sua acção. Perante a diversidade de experiências do meio natural, somos confrontados com uma alteridade que desafia o nosso conforto e a nosso sentimento de si, conferindo-nos um sentido de proporção acerca do nosso lugar no mundo; perante a alteridade da natureza, sentimo-nos movidos a integrar na nossa própria vida os ritmos maiores que a percorrem e constituem.

A literatura portuguesa, tal como decerto as restantes, regista por vezes o esplendor dessa experiência do belo natural e do modo como retira o sujeito de um torpor confortável, lançando-o para um exame interior de alcance ético. O que nos atém aqui é o reconhecimento do poder das formas naturais para surpreenderem no sujeito um alargamento da imaginação moral por outros seres, o que se reflecte na postura ética do sujeito perante si e perante outros agentes morais.

O potencial pedagógico da natureza para remoçar o sujeito; o apelo do bravio e do simples para dissipar as agruras urbanas; para promover uma hierarquia de fins e reavaliar o reino dos meios que a cornucópia

18 Cf. Rolston III 1979: 25. 
tecnológica provê estão magistralmente ilustrados no livro $A$ Cidade e as Serras, de Eça de Queirós. O protagonista do romance é Jacinto, português herdeiro de uma família de fidalgos e que assentou arraiais em Paris; ali vive no maior dos faustos e opulências; no seu apartamento possui uma biblioteca com trinta mil volumes e todas as comodidades e faz jus ao credo na ciência e na tecnologia como vias predilectas para a elevação do homem à sua supina realização civilizacional e pessoal; Jacinto encarna pois a fé na promessa de vida boa associada ao progresso logrado através da tecnologia; desconfia da natureza concreta, das suas trevas hostis, da sua inaptidão a ser domesticada.

Apesar de o contexto histórico ser o do século XIX, José Fernandes, o narrador-personagem, descreve o manancial de engenhocas e geringonças que rodeavam Jacinto em diversas passagens ${ }^{19}$ enquanto ilustra o enfado e o fastio que parecem acometer o seu amigo. $\mathrm{O}$ humor burlesco perante o ridículo dos instrumentos que falham, o modo como invadiam e entretinham as mais pequenas e miúdas necessidades de Jacinto e dos seus convivas mostram como uma existência aliviada de todos os esforços e entraves pode redundar em frustração e apatia ${ }^{20}$. O manancial de artíficios, adaptado como puro meio de satisfazer necessidades e obter a desejada felicidade, torna-se em fátuo fim, gerando dependências inescapáveis e um tédio crescente ${ }^{21}$. Efectivamente, Jacinto, depois de devorar volumes de cartapácios com as ideias do seu tempo, rodeado de apetrechos e luxos, sucumbe à acédia e ao pessimismo de Schopenhauer. Tudo the parece uma "maçada" e uma "seca" e perante a insatisfação pela necessidade infinda do supérfluo, declara que "nada vale a pena"; o diagnóstico é óbvio: Jacinto "sofre de fartura" 22 . Eis porém que, empurrado, por acontecimentos fortuitos, de Paris para a casa de família em Tormes, no coração do Douro, Jacinto rejuvenesce em contacto com a paisagem singela. Lentamente morigerado, afastando-se das abstracções cinzentas que sobre ele pairavam, deixa-se enlevar pela experiência do belo natural; e é aí que, ao invés de se afastar da civilização, ele aprende a regrá-la e a dar-lhe um espaço próprio:

A essa hora, enquanto pelo arvoredo mudo os mais agitados pardais dormiam, e o Sol mesmo parecia repousar, imóvel na rutilância da sua luz, Jacinto, com o espírito acordado, — ávido de sempre gozar, agora que

19 Cf. Queirós 1991: 27.

20 Ibid. p. 72.

${ }^{21}$ Ibid. p. 80.

22 Ibid. p. 80. 
reconquistara essa faculdade - tomava com delícia o seu livro. Porque o dono de trinta mil volumes era agora, na sua casa de Tormes, depois de ressuscitado, o homem que só tem um livro. Essa mesma Natureza, que o desligara das ligaduras amortalhadas do tédio, e lhe gritara o seu belo ambula — caminha! — também certamente lhe gritara et lege, e lê. ${ }^{23}$

\section{A natureza em Albert Borgmann}

Segundo Borgmann, a natureza no continente norte-americano sempre foi um interesse perene e uma referência do discurso díctico, através do qual vários apelos foram feitos ${ }^{24}$. Isto deve-se não só à eloquência da própria natureza mas ao facto de ela em si constituir um domínio que escapa ao reino da tecnologia.

A natureza parece poder constituir-se como um desafio à tecnologia porque é precisamente antitética ao paradigma do dispositivo, não estando invadida por ele e resistindo-lhe de maneiras sempre subtis; ela é portanto um desafio para a tecnologia dentro do seu próprio enquadramento e para esse próprio enquadramento; a tecnologia propõe-se à resolução de desafios de maior controlo ou maior captura de recursos, como é o caso da instalação de barragens em rios, redes eléctricas, mineração ou desflorestação em áreas protegidas ou em locais que desconhecemos; e contudo, a natureza são também aquelas derradeiras áreas onde podemos encontrar e viver com uma alteridade que ainda escapa à rasura ontológica e à voragem transformadora de seres em dispositivos.

Como o ponto anterior mostrou, a natureza possui um esplendor que é por vezes captado pelo discurso díctico. Quando estamos na natureza, aprendemos algo não só acerca de nós próprios, mas acerca da tecnologia; verificamos, aliás, como ambos estão ligados. Ao conhecermo-nos fora do conforto que ela providencia, dos hábitos em que nos enraizou, das expectativas com que nos condicionou, podemos intuir como ela nos vem constituindo e relativizar a importância das nossas preocupações num contexto normal em que estamos permeados por artefactos. Como referido, uma das mais pungentes propostas da tecnologia é aniquilar o espaço e o tempo, reduzindo as limitações dos lugares e da espera até estas se tornarem negligenciáveis; esta aniquilação seria obtida com a satisfação instantânea e com a disponibilidade ubíqua dos bens.

${ }^{23}$ Ibid. p. 178.

24 Cf. Borgmann 2006: 22 e 129. 
Ora, Borgmann aponta que na natureza há um tempo e um espaço próprio que nos são restaurados; sem horários ou obrigações, somos devolvidos ao ritmo diário da terra; o sol, por exemplo, torna-se o orientador das nossas actividades, pautando aquilo que podemos ou não fazer através do calor e da luz. Todas as actividades que possamos executar ao ar livre, na natureza, estão assim marcadas pelo sol e pela baliza temporal e espacial que ele nos proporciona. A nossa experiência da natureza é, enfim, limitada.

E é a existência de limites, a precisão de fronteiras, que permitem que nos situemos na natureza num lugar específico e que o conheçamos através da porosidade dos nossos sentidos. Borgmann classifica esta riqueza de sentidos e dimensões a que a natureza se presta como profun$d a$; a profundidade da natureza contrasta, afinal, com o modo como a tecnologia produz superfícies, apropriando-se de coisas outrora ricas em contexto e em ligações ontológicas para as tornar em bens cuja modo de aparição está inacessível ${ }^{25}$.

A natureza, contudo, não está somente confinada a santuários de conservação e preservação; ela pervade inúmeras das nossas actividades, situando-se a montante dos nossos hábitos, na periferia da consciência ${ }^{26}$. Em Borgmann, estar na natureza também nos restaura uma perspectiva sobre os seres e as coisas que nos afasta do modo tecnológico de os tomar, de acordo com o paradigma do dispositivo. Habituados à divisão entre meios e fins que o paradigma do dispositivo fornece, abstemo-nos de verificar o todo de uma certa prática, estilhançando-a em termos de meios e de fins.

Ao olharmos tecnologicamente para uma refeição, por exemplo, podemos preocuparmo-nos somente com o seu valor nutricional e para o modo como o seu aspecto e o seu sabor se adequam ao nosso paladar. Além do nosso horizonte de apreciação, contudo, reside o modo como esses alimentos foram cultivados, colhidos e distribuídos; as ciências sociais e naturais podem fornecer-nos factos acerca de impactes ambientais ou estruturas laborais que tendem a ficar na sombra do preço de cada alimen-

25 Podemos assinalar semelhanças entre a transformação pela tecnologia das coisas em dispositivos e do modo como parasita o reino dos fins da acção humana com a caracterização que Simmel faz do dinheiro; este suscita a indistinção ontológica e moral, instalando a ignorância acerca do valor entitativo dos particulares e instigando, pela sua essência, a indiferença perante as coisas e o anelo pelo ilimitado; a recordação da tecnologia e do dinheiro como meios afins aos propósitos humanos tem de ser equacionada por um despertar do valor último e intrínseco dos seres e das coisas a áreas de acção confinadas. Cf. Simmel 2009.

26 Cf. Borgman 1993: 120-121. 
to; mas mesmo com essa informação tácita, sabemos que aquilo que no quotidiano concorre mais directamente para a satisfação secreta de um comensal é a predisposição espiritual para ele se instalar na instantaneidade de ser servido, na disponibilidade de requerer mais refeições independentemente da proveniência dos seus constituintes e na ubiquidade de poder comer o que quiser, quando quiser e em qualquer metrópole do mundo, com segurança e facilidade.

É contudo na natureza que permitimos que as coisas sejam elas próprias por completo, em todas as suas dimensões, deixando-as assim terem a sua própria voz, tornando-se mais profundas precisamente por a sua existência não ter de estar relacionada com os nossos propósitos utilitários; e é esse reconhecimento da alteridade de outros seres, fauna ou flora, inscritos num todo biofísico que adquire formas esteticamente relevantes, que tem valor propedêutico, de educação moral, de inculcação de virtudes; é na natureza e na excepção que ela constitui ao nosso modo de habitar tecnológico que se estabelece o primado de uma relação em que não nos vemos a nós próprios como estando perante meros artefactos tecnológicos, como consumidores dos bens que eles disponibilizam; deixamos, ainda que temporariamente, de ser herdeiros de uma longa história de conquista e controlo, podendo entregarmo-nos à fragilidade transitória de entender, através do cansaço e dos sentidos, a diversidade de formas animais e vegetais; apercebemo-nos de que um envolvimento aturado com ela permite uma reavaliação de como a habitamos, aprendendo a respeitá-la como algo em si próprio, com valor intrínseco.

O exemplo da natureza garante assim que haja o reconhecimento de uma eloquência e um brilho particular a várias coisas que invocam o nosso envolvimento; mas, e aqui está um dos pontos mais fundamentais na análise de Borgmann, esse reconhecimento acontece num contexto tecnológico. Só podemos ir à natureza e exercer práticas de ar livre porque estamos imersos num mundo que ocasiona os meios logísticos e materiais necessários para viajar e regressar em tempo útil e de maneira lúdica; talvez nunca nos sintamos verdadeiramente em risco, abandonados e entregues apenas a nós próprios; contudo, ao abreviarmos a dependência da tecnologia, permitimos um envolvimento com as coisas de uma maneira diferente, de modo talvez mais maduro porque reconhecemos que a tecnologia é uma dádiva que requer disciplina para não se tornar um fardo opressor dessas realidades que mais nos apelam. 


\section{Da reforma da tecnologia}

O que pode a experiência da natureza propor para uma reforma da tecnologia? Não se trata de transferir ou deslocar as noções comuns do divino da religião para a natureza ${ }^{27}$. Borgmann entende que mesmo assim nada de prático resultaria; trata-se afinal de aprender uma outra vez a reconhecer e a respeitar a alteridade como algo que pode existir, subsistir e florescer sem a nossa intervenção e que podemos inclusive apreender como maior do que nós; há uma humildade maior que pertence àquele que sabe admirar sem malograr algo que lhe pode ser proveitoso, permitindo que esse algo granjeie o seu próprio esplendor. A natureza é uma dessas coisas e Borgmann deixa claro que pode não ser a única ou o reino final onde podemos encontrar a reverência por um florescimento; é, no entanto, talvez o começo mais claro dessa descoberta e da reforma virtuosa das nossas próprias vidas.

Como já deverá ter ficado implícito pelo contraste com o paradigma do dispositivo, existem certas coisas e práticas que podem porém adestrar-nos e inveterar-nos ao ponto de podermos propor através delas uma reforma da tecnologia. Para Borgmann são essas coisas e práticas, ditas focais, que nos permitem readquirir um "centro" pois dizem respeito às coisas que realmente orientam qualquer vida. Voltando à noção de centro e ao exemplo da lareira, o étimo de focal é $f_{o c u s}{ }^{28}$, o que nos remete para um centro com luz, calor e de práticas quotidianas em cada lar e ante o qual cada família se reunia e se ordenava. A proposta do autor passa no entanto por sublinhar que as coisas e as práticas focais são mais valorizadas em ambientes tecnológicos desde que aprendamos e entendamos que elas requerem uma prática para que possam prosperar e tornar-se num hábito.

Tal como ilustra a experiência da natureza, o regresso às coisas e práticas focais não deverá nem poderá ser assim uma rejeição da tecnologia nem uma forma de escapar dela, mas um reconhecimento daquilo que ela é. Sem uma prática focal ou uma acção comprometida, a nossa vida, segundo Borgmann, não está orientada ou ordenada focalmente ${ }^{29}$. Para termos um modo de vida que logre atingir a excelência, uma disposição virtuosa, temos de estar arreigados numa prática ${ }^{30}$; só através de práticas podem os efeitos perniciosos da tecnologia ser abafados ou recontextua-

\footnotetext{
Cf. Borgmann 1984: 190.

28 Em português não é incomum usar-se fogo para designar um lar ou uma casa.

29 Cf. Borgman 1984: 155.

30 Cf. Borgmann 2006: pp. 90-92.
} 
lizados. As práticas focais são aquelas que restauram uma integridade ou uma profundidade nas nossas vidas as quais, imersas no paradigma do dispositivo, tendem a ficar afastadas dessas características; porque uma prática guarda e preserva uma coisa focal, actualiza o seu mundo com outros seres humanos e defende-o da intrusão tecnológica; cada prática renova o uso de cada coisa focal e cria um espaço e um tempo próprio à coisa focal nas nossas vidas ${ }^{31}$.

Portanto, a reforma que Borgmann propõe não implica uma recusa da tecnologia mas uma restrição do seu alcance corrente; esta restrição pressupõe a centralidade das coisas e das práticas focais como capazes de conduzir a lógica do dispositivo para uma periferia que não lhe confira mais o protagonismo mediador com que ele açambarca a vida contemporânea; recontextualizados e reequilibrados perante a importância das coisas e práticas focais, os dispositivos retraem-se à medida desse despojamento. As reformas, ao nível individual, podem possuir três direcções: a primeira é a criação de um espaço central para a coisa ou prática focal, seja ela diária ou não, como tocar um instrumento, caminhar ou preparar uma refeição de mesa com os respectivos e invioláveis tempos próprios; a segunda direcção de reforma é a simplificação da vizinhança vivencial do que rodeia a prática focal; finalmente, a terceira direcção é a extensão da esfera do envolvimento com a prática focal a outras áreas da vida, devido à compreensão da vitalidade do envolvimento heurístico com as coisas e práticas focais; estas três direcções convergem nas noções da máxima aprendizagem de tarefas e da autonomia daí advinda ${ }^{32}$.

A natureza para Borgmann adquire assim este valor de alteridade que permite uma heurística sobre nós próprios e de como nos queremos situar em relação à tecnologia; a experiência da natureza permite que aceitemos não só a tecnologia mas também que aprendamos a limitá-la no nosso interesse. Porque aquilo que a natureza mostra é precisamente a riqueza de um envolvimento estético profundo relativamente despido de um protagonismo tecnológico e que como tal pode fundamentar um despojamento tecnológico através do envolvimento em práticas e coisas focais. Só quando soubermos que há tarefas que nos interessam por si próprias, independentemente de as conceptualizarmos em meios e fins, é que estaremos aptos a limitar e a reformar a tecnologia através de práticas e coisas focais. É neste ponto que entendemos fundamental assinalar a permanente mediação moral que a tecnologia introduz e que a ética ambiental deverá ter em conta.

$31 \quad$ Ibid.p. 196.

$32 \quad$ Ibid. p. 222. 


\section{REFERÊNCIAS BIBLIOGRÁFICAS}

Beckert, Cristina (2012), Ética, Lisboa, Centro de Filosofia da Universidade de Lisboa. Borgmann, Albert (1984), Technology and the Character of Contemporary Life: A Philosophical Inquiry, Chicago, University of Chicago Press.

- (1993), Crossing the Postmodern Divide, Chicago, University of Chicago Press.

- (2006), Real American Ethics. Taking Responsibility for Our Country, Chicago, University of Chicago Press.

Queirós, Eça de, (1975) A Cidade e as Serras (25 edição), Lisboa, Livros do Brasil. Rolston III, Holmes (1979), “Can and Ought We to Follow Nature?”, Environmental Ethics, 1, 7-30.

Simmel, Georg (2009), Psicologia do Dinheiro e outros ensaios, Lisboa, Edições Texto \& Grafia.

\section{SUMÁRIO}

Neste trabalho pretendemos examinar o papel que a natureza adquire na filosofia da tecnologia de Albert Borgmann. Segundo o autor, a vida contemporânea foi tomada pelo paradigma do dispositivo: a tecnologia segue um padrão que transforma as dimensões de coisas, ricas em contexto, em dispositivos; estes compõem-se de bens, disponíveis e sem exigências de envolvimento; e de mecanismos, que escondem o modo como os recursos naturais são usados. Este padrão não torna explícita a noção de vida boa promovida. A experiência da natureza ilustra porém algo que, pela sua alteridade, escapa ao paradigma do dispositivo; a natureza é algo que pode florescer e atingir o seu esplendor sem a nossa intervenção e sem os nossos propósitos utilitários; essa eloquência pode levar-nos a uma reforma da tecnologia através da aquisição de um centro; este centro exige porém ser cultivado através de práticas e coisas focais, para se tornar num hábito estruturante.

Palavras-chave: tecnologia - natureza - ética - estética - virtudes 


\begin{abstract}
In this paper we intend to evaluate the role that nature has in the philosophy of technology of Albert Borgmann. According to the author, contemporary life has been taken by the device paradigm; technology follows a pattern that transforms the rich dimensions of things into devices; these are composed of commodities, easily available and without demanding any effort, and mechanisms, hiding the ways how natural resources are used. This pattern does not make explicit the promoted notion of the good life. The experience of nature shows how something that escapes the device paradigm can endure and flourish beyond our utilitarian purposes; its eloquence can thus take us to propose a reform of technology through the notion of a center; however, this center demands to be cultivated through focal things and practices in order to turn in to a structuring habit of our lives.
\end{abstract}

Keywords: technology - nature - ethics - aesthetics - virtues 